\title{
P-0280 HD-6277 is a selective GPR40 agonist with no drug-induced liver injury compare with TAK-875
}

\author{
SUN HEE LEE, CHUN HWA KIM, GOEUN YANG, HYO-SUN CHOI, SEUNG JUN \\ KANG, DOO-YOUNG KIM, HYOUNG EUN YU, JIN YANG, JAE-KEOL RHEE, \\ DAE-HOON KIM
}

HYUNDAI PHARM, Seoul, Republic of Korea

\section{Background}

TAK-875, a selective G-protein-coupled receptor 40 (GPR40) agonist, improves glucose tolerance hyperglycemia. However, TAK-875 was withdrawn from phase 3 clinical trials due to drug-induced liver injury (DILI). They asuured the cause of DILI by TAK- 875 was to change the homeostasis of bile acid.

\section{AIM}

We should consider whether DILI by TAK- 875 is assosiated with GPR40. The hepatotoxicity of TAK-875 is not a class effect of the GPR40 agonist, and HD-6277 is safety.

\section{Material and methods}

In this study, HD-6277 (a novel selective GPR40 agonist) was evaluated DILI with TAK-875 in vitro/vivo study. HD-6277 was assessed phospholipidosis in HepG2 cell. We examined the inhibitory effects on hepatobiliary transporters to explore the mechanisms underlying its hepatotoxicity. To evaluate the potential liver toxicity of HD-6277 and TAK-875 administered to Beagle dogs once daily orally by capsule in Beagle Dogs for a period of 2-weeks. And ALT levels were investigated in dietinduced obesity rats induced by ethanol-induced liver injury, following each drug's administration for 2 weeks.

\section{Results}

HD-6277 was not induced phospholipidosis in HepG2 cell by $100 \mathrm{uM}$, but TAK-875 was. In hepatobiliary transporter inhibitory assay, HD-6277 showed safer value in influx and efflux transporters (NTCP; Na+/taurocholate cotransporting polypeptide, OATPs; organic anion transporter polypeptides, BSEP; human bile salt export pump, MRP2; multidrug resistance-associated protein 2) than TAK-875. TAK-875 induced liver changes consisting of multifocal bile duct proliferation(hyperplasia/hypertrophy). BUT HD-6277 did not. Moreover, in alcoholic fatty liver model, TAK-875 enhanced ALT level.
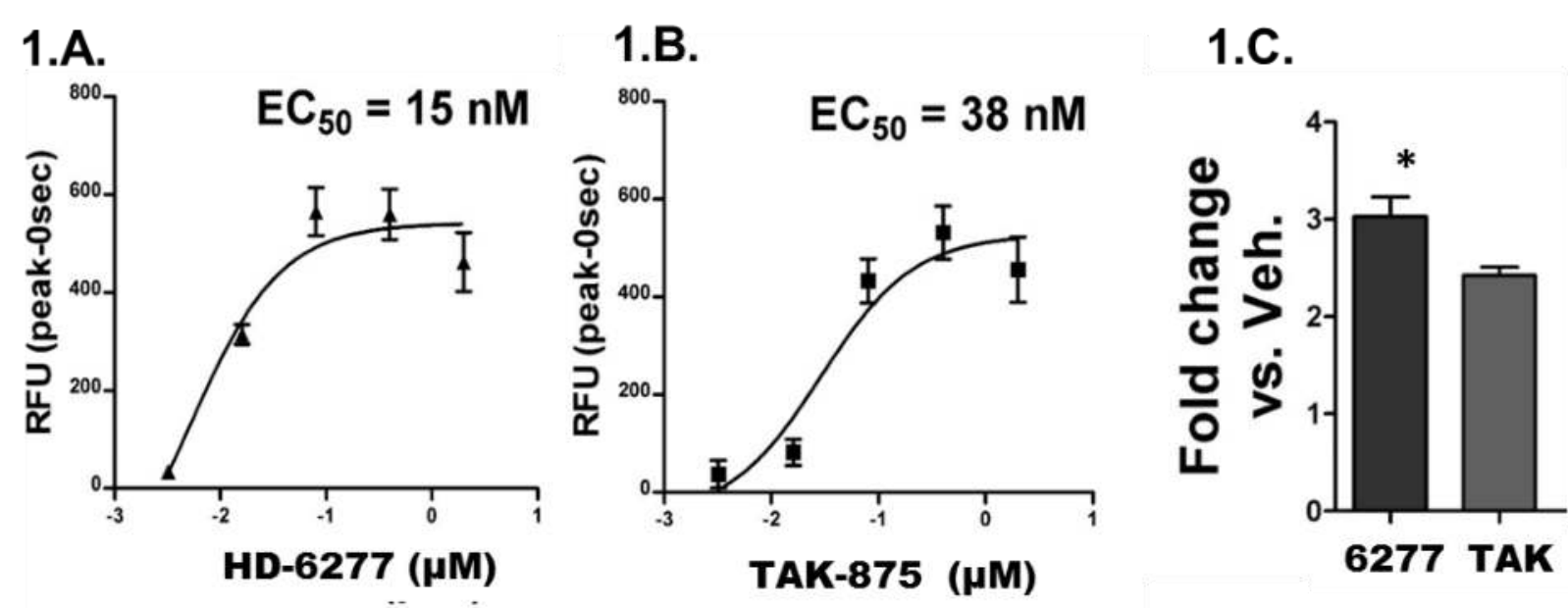

Fig.1 Pharmacological comparison of HD-6277 and TAK-875

\begin{tabular}{|c|c|c|c|c|}
\hline \multirow{2}{*}{$\begin{array}{c}\text { Bile acid } \\
\text { Transporters }\end{array}$} & \multicolumn{2}{c|}{$\begin{array}{c}\text { Hyundai } \\
\text { Pharm. }\end{array}$} & \multicolumn{2}{c|}{$\begin{array}{c}\text { Toxicological } \\
\text { Sciences, } \\
\text { 157(1),50-61, 2017. }\end{array}$} \\
\cline { 2 - 6 } & $\begin{array}{c}\text { TAK- } \\
\mathbf{8 7 5}\end{array}$ & $\begin{array}{c}\text { HD-627 } \\
\mathbf{7}\end{array}$ & TAK-875 & $\begin{array}{c}\text { TAK-875 } \\
\text {-Glu }\end{array}$ \\
\hline MRP2 & N.D. & $\mathbf{8 1 . 0}$ & N.T. & 9.0 \\
\hline MRP3 & $\mathbf{3 9 . 0}$ & N.D. & 14.7 & 3.4 \\
\hline MRP4 & N.T. & N.T. & 11.7 & 6.7 \\
\hline NTCP & $\mathbf{2 . 5}$ & $\mathbf{6 . 0}$ & 2.0 & 2.4 \\
\hline hOATP1B1 & $\mathbf{0 . 2}$ & $\mathbf{1 . 6}$ & 2.4 & N.T. \\
\hline hOATP1B3 & $\mathbf{0 . 4}$ & $\mathbf{1 . 8}$ & 11.6 & N.T. \\
\hline hBSEP & $\mathbf{7 . 6}$ & $\mathbf{2 8 . 9 *}$ & 14.3 & 41.6 \\
\hline
\end{tabular}

N.T.: Not Treated; N.D: Not Determined; *: expected value in solubility of $30 \mu \mathrm{M} ;$ TAK-875-Glu (TAK-875-glucuronide): metabolite of TAK-875; h: human;

r: rat;

$d: \operatorname{dog}$

Table.1 Hepatobiliary Transporter IC50 values

\section{Conclusion}

These findings suggest that HD-6277 and TAK-875 showed different inhibitory effects on hepatobiliary transporters. Probably, HD-6277 may be less effects to DILI than TAK-875. It was reported that TAK-875 induced liver toxicity may not related to a class effect of the GPR40 agonist.

\section{Acknowledge}

This research was supported by a grant of the Korea Health Technology R\&D Project through the Korea Health Industry Development Institute (KHIDI), funded by the Ministry of Health \& Welfare, Republic of Korea (grant number : HI14C2710). 